\title{
Ketoprofen-loaded Eudragit electrospun nanofibers for the treatment of oral mucositis
}

\author{
This article was published in the following Dove Press journal: \\ International Journal of Nanomedicine \\ 27 March 2017 \\ Number of times this article has been viewed
}

\author{
Rana Ihab Reda' \\ Ming Ming Wen ${ }^{2}$ \\ Amal Hassan El-Kamel' \\ 'Department of Pharmaceutics, \\ Faculty of Pharmacy, Alexandria \\ University, ${ }^{2}$ Department of \\ Pharmaceutics, Faculty of \\ Pharmacy and Drug Manufacturing, \\ Pharos University in Alexandria, \\ Alexandria, Egypt
}

\begin{abstract}
Purpose: The purpose of this study was to formulate ketoprofen (KET)-loaded Eudragit L and Eudragit S nanofibers (NFs) by the electrospinning technique for buccal administration to treat oral mucositis as a safe alternative to orally administered KET, which causes gastrointestinal tract (GIT) side effects.
\end{abstract}

Materials and methods: NFs were prepared by electrospinning using Eudragit L and Eudragit S. Several variables were evaluated to optimize NF formulation, such as polymer types and concentrations, applied voltage, flow rate and drug concentrations. Differential scanning calorimetry (DSC), Fourier transform infrared spectroscopy (FTIR) and scanning electron microscopy (SEM) and analyses of drug contents, hydration capacity, surface $\mathrm{pH}$, drug release and ex vivo permeation were performed to evaluate the NFs. The selected formulation (F1) was evaluated in vivo on induced oral mucositis in rabbits.

Results: SEM revealed that $20 \%$ polymer formed smooth and bead-free NFs. DSC results confirmed the amorphous nature of KET in the NFs. FTIR confirmed hydrogen bond formation between the drug and polymer, which stabilized the NFs. Both formulations (F1 and F2) had an acceptable surface $\mathrm{pH}$. The drug loading was $>90 \%$. The amount of KET released from NF formulations was statistically significantly higher $(P \leq 0.001)$ than that released from the corresponding solvent-casted films. The complete release of KET from F1 occurred within 2 hours. Ex vivo permeation study revealed that only a small fraction of drug permeated from F1, which was a better candidate than F2 for local buccal delivery. In vivo evaluation of F1 on oral mucositis induced in rabbits demonstrated that F1 reduced the clinical severity of mucositis in rabbits under the current experimental conditions. The attenuated clinical severity was accompanied by a marked reduction in inflammatory infiltrate and re-epithelization of the epithelial layer.

Conclusion: Eudragit L100 nanofibers (EL-NF) loaded with KET (F1) suppressed the inflammatory response associated with mucositis, which confirmed the efficacy of local buccal delivery of KET-loaded EL-NF in treating oral mucositis.

Keywords: nanofibers, electrospinning, ketoprofen, Eudragit, oral mucositis

\section{Introduction}

Oral mucositis is an inflammatory condition of the oral mucosa following chemotherapy or radiotherapy. The severe ulceration, pain and erythematous lesions associated with oral mucositis often cause significant difficulties for patients in eating and drinking, leading to weight loss, fatigue and impaired quality of life. In addition, these complications may lead to prolonged hospitalization and require special care, such as parenteral or gastric nutrition. ${ }^{1}$ In more severe oral mucositis cases, a reduction in the chemotherapy dose or imposing a treatment break in radiation therapy may be necessary, which can lead to the development of drug resistance and suboptimal
Correspondence: Amal Hassan El-Kame Department of Pharmaceutics, Faculty of Pharmacy, Alexandria University, Mazareta, Khartoum Square, Alexandria 21521, Egypt Tel +20 I00 50805 I0 Emailamalelkamel@yahoo.com (c) (1) (5) 2017 Reda et al. This work is published and licensed by Dove Medical Press Limited. The full terms of this license are available at https.//wwww.dovepress.com/terms.php
and incorporate the Creative Commons Attribution - Non Commercial (unported, v3.0) License (http://creativecommons.org/licenses/by-nc/3.0/). By accessing the work you (c)
hereby accept the Terms. Non-commercial uses of the work are permitted without any further permission from Dove Medical Press Limited, provided the work is properly attributed. For permission hereby accept the Terms. Non-commercial uses of the work are permitted without any further permission from Dove Medict
for commercial use of this work, please see paragraphs 4.2 and 5 of our Terms (https://www.dovepress.com/terms.php). 
treatment outcome and can negatively influence the cancer treatment prognosis. Furthermore, patients with damaged oral mucosa and reduced immunity resulting from chemotherapy and radiotherapy are prone to develop infections in the mouth, which can be a life-threatening condition. ${ }^{2}$

According to the National Cancer Institute guidelines, the analgesic treatment for mucositis following head and neck cancer starts with non-steroidal anti-inflammatory drugs (NSAIDs). ${ }^{3}$ The use of NSAIDs for the treatment of a number of oral cavity pathologies, such as gingivitis, periodontitis, stomatitis and oral ulcers, is common. ${ }^{4}$ However, the oral administration is usually associated with significant unwanted systemic side effects, particularly gastrointestinal (GI) bleeding and renal dysfunction. ${ }^{5}$ Cancer patients undergoing chemotherapy and radiation therapy are frequently neutropenic and thrombocytopenic. The systematic treatment of the pain due to oral mucositis may further complicate the side effects of NSAIDs. Therefore, local treatment is preferred since it delivers more drugs to the target tissue with less systemic absorption.

Among various topical NSAIDs that show potential efficacy in treating oral mucosal lesions, ketoprofen (KET) exhibits a greater potency relative to other agents in blocking human prostaglandin E2 (PGE2) synthesis in vitro. ${ }^{6}$ In addition, it has the added advantage of directly inhibiting monocytes and macrophages, which are involved in the synthesis of PGE2. Besides its ability to block the cyclooxygenase pathway, in vitro reports have also suggested an anti-lipoxygenase activity and hence the added ability of the drug to inhibit leukotriene formation. Other unique anti-inflammatory effects of KET include its anti-bradykinin activity, stabilization of lysosomal membranes and suppression of leukocyte migration. ${ }^{7}$ Local buccal delivery of KET could be considered as a safe alternative route to oral administration for patients with oral mucositis to reduce the systemic absorption and side effects.

To improve oromucosal delivery of NSAIDs, several new dosage forms have been developed, such as mucoadhesive films,${ }^{89}$ proniosomal gel, ${ }^{10}$ liquid crystalline film, ${ }^{11}$ buccal tablet, ${ }^{12}$ electrospun nanofibers (NFs) ${ }^{13}$ and many others. Among these drug delivery systems, electrospun NFs have attracted increasing attention in the recent years as novel carrier systems. ${ }^{14,15}$

To our knowledge, there has been little work in the literature focused on the electrospun NFs for oral mucosal application, and no research has studied the use of electrospun NSAID-loaded NFs to address the important issue of oral mucositis treatment through local buccal administration. The main objective of this study was to formulate and evaluate locally applied mucoadhesive buccal KET NFs for pain and inflammation management of oral mucositis as a safe alternative dosage form to orally administered drug, that can be easily applied by patients.

\section{Materials and methods Materials}

The materials used in this study were KET (El-Amriya Pharmaceutical Co., Alexandria, Egypt); Eudragit L100 (EL), Eudragit S100 (ES) and Eudragit RS100 (Evonik Röhm Pharma GmbH, Darmstadt, Germany); ethanol 96\% (El-Nasr Pharmaceutical Co., Alexandria, Egypt); acetic acid and formalin (El Gomhouria Co., Alexandria, Egypt); ketamine (Alfasan, Woerden, the Netherlands) and xylamine (Adwia Co., Cairo, Egypt). All other chemicals were of reagent grade.

\section{Animals}

Albino rabbits (1.7-2 kg) were provided by the animal facility of the Institute of Graduate Studies and Research, Alexandria University.

\section{Preparation of the electrospun NFs}

The homogeneous electrospun polymer solutions were prepared by dissolving different polymers, including ES and EL in ethanol, at different concentrations of $10 \%, 15 \%, 20 \%$ and $25 \%$ (w/v) using a magnetic stirrer (DAIHAN Scientific Co., Ltd., Seoul, Korea) for 1 hour at room temperature until complete dissolution of the polymer. To prepare drug-loaded polymer solutions, KET was added at different concentrations of $10 \%$, $15 \%$ and $20 \%(\mathrm{w} / \mathrm{v})$ to the polymer solutions. The mixture was stirred for a further 30 minutes at room temperature.

Prior to electrospinning, the viscosity of the prepared polymeric solutions was measured at room temperature with a viscometer (RV-TD, spindle S15; Brookfield Engineering Laboratories, Inc., Middleboro, MA, USA) at different shear rates.

The electrospinning apparatus setup was composed of high-voltage DC power supply, a pump and a $10 \mathrm{~mL}$ syringe with a stainless steel blunt needle $(18 \mathrm{G})$ kept at a horizontal position of $90^{\circ}$ and at a distance of $10 \mathrm{~cm}$ from the collector surface. The positive high voltage was connected to the spinneret tip, and the negative voltage supply was connected to the metal collector covered with aluminum foil to collect the ultrafine NFs. The electrospinning process was conducted at ambient room temperature and humidity. The prepared polymer solutions were loaded in the syringe and delivered at different flow rates and voltages. The effects of different variables on the structural characteristics of the NFs 
were studied, which included polymer types and concentrations $(10 \%-25 \% \mathrm{w} / \mathrm{v})$, applied voltage $(0.5$ and $1 \mathrm{~mL} / \mathrm{h})$, flow rates $(0.5-2 \mathrm{~mL} / \mathrm{h})$ and drug concentrations (10\%-20\%). Polymer films with the same quantitative composition of NFs were also prepared for comparison study.

\section{Scanning electron microscopy (SEM)}

The morphology of NFs was examined by SEM (JSM-5300; JOEL, Tokyo, Japan). Samples were mounted on metal stubs and sputter coated with gold using an ion-sputtering coater for 30 minutes prior to examination. The diameter of the electrospun NFs was measured from the SEM image of the sample by SEM image analysis software.

\section{Determination of drug content}

Prepared NFs were cut into $30 \mathrm{mg}$ mass and dissolved in $10 \mathrm{~mL}$ ethanol using a magnetic stirrer for 5 minutes until complete dissolution of the NFs. The drug content was analyzed at $255 \mathrm{~nm}$ using a ultra violet spectrophotometer (Shimadzu spectrophotometer; Shimadzu Co., Kyoto, Japan) after filtration and suitable dilution of the sample. The unknown concentration was determined using a preconstructed validated calibration curve in ethanol. The entrapment efficiency and drug loading were calculated as follows: ${ }^{16}$

Entrapment efficiency $(\% \mathrm{w} / \mathrm{w})=$ $\frac{\text { Weight of drug in the nanofiber }}{\text { Theoretical weight of drug in the nanofiber }} \times 100$

Drug loading $(\% \mathrm{w} / \mathrm{w})=$ $\frac{\text { Weight of drug in nanofibers }}{\text { Weight of nanofibers taken }} \times 100$

\section{Differential scanning calorimetry (DSC)} Accurate weights (5 mg) of KET, ES, EL and KET-loaded Eudragit S100 nanofibers (ES-NF) and Eudragit L100 nanofibers (EL-NF) were analyzed by DSC-6 (PerkinElmer Instrument, MA, USA). Samples were spread and hermetically sealed in aluminum pans and heated at a constant rate of $5^{\circ} \mathrm{C} / \mathrm{min}$ over a temperature range of $25^{\circ} \mathrm{C}-400^{\circ} \mathrm{C}$. Inert atmosphere was maintained by purging nitrogen as a blank gas at a flow rate of $20 \mathrm{~mL} / \mathrm{min}$.

\section{Fourier transform infrared spectroscopy (FTIR)}

Samples (2 mg) of KET, ES, EL and KET-loaded ES-NF and EL-NF were mixed with $200 \mathrm{mg}$ of pure potassium bromide powder and compressed into disks. Analyses were performed by FTIR (PerkinElmer Instrument) from 350 to $4,400 \mathrm{~cm}^{-1}$ at room temperature.

\section{Measurement of surface $\mathrm{pH}$}

NFs were cut into $1 \mathrm{~cm}^{2}$ pieces, which were left to swell for 2 hours on the surface of an agar plate. The surface $\mathrm{pH}$ was measured by bringing a combined glass electrode (Schott Geräte, Mainz, Germany) in contact with the surface of the NFs, allowing it to equilibrate for 1 minute.

\section{Measurement of hydration capacity}

NF pieces $(30 \mathrm{mg}$ ) were held on a stainless steel mesh and immersed in $10 \mathrm{~mL}$ phosphate buffer ( $\mathrm{pH}$ 6.8) simulating salivary $\mathrm{pH}$. The swelling behavior was observed at predetermined time intervals. Samples were removed with the mesh, blotted off carefully on tissue papers to remove the surface-adhered liquid droplets and reweighed to constant weight. The percentage of water uptake was calculated from the following equation: ${ }^{17}$

$$
\text { Water uptake }(\%)=\frac{\mathrm{W}_{2}-\mathrm{W}_{1}}{\mathrm{~W}_{1}} \times 100
$$

where $\mathrm{W}_{2}$ is the weight of the hydrated NFs and $\mathrm{W}_{1}$ is the initial weight of NFs.

\section{Mucoadhesion test}

The mucoadhesive properties of the NFs were evaluated by the modified balance method through measuring the detachment forces between the NFs loaded with KET $\left(1 \mathrm{~cm}^{2}\right)$ and chicken pouch mucosal surface. ${ }^{18}$ The weight of added water in grams required to detach the NFs from the mucosal surface was measured. The force required to break the adhesive bond per unit area was calculated using the following equation: ${ }^{18}$

$$
\mathrm{F}=\frac{\mathrm{W}_{\mathrm{w}} \times \mathrm{g}}{\mathrm{A}}
$$

where $\mathrm{F}$ is the mucoadhesive force (detachment force) in dyne $/ \mathrm{cm}^{2}, \mathrm{~W}_{\mathrm{w}}$ is the detachment weight in grams (weight of water added), $\mathrm{g}$ is the acceleration due to gravity in $\mathrm{cm} / \mathrm{s}^{2}$ and $\mathrm{A}$ is the surface area of the NFs in $\mathrm{cm}^{2}$.

\section{Ex vivo mucoadhesion time}

The chicken buccal pouches were fixed to the internal side of a beaker with cyanoacrylate glue. A piece of the NFs containing $25 \mathrm{mg}$ KET was first moistened with a few drops 
of phosphate buffer ( $\mathrm{pH}$ 6.8) and then fixed to the chicken buccal mucosal surface by applying a light force with the finger tip for 20 seconds. The beaker was then filled with $50 \mathrm{~mL}$ of phosphate buffer solution $\left(37^{\circ} \mathrm{C}\right)$. After 2 minutes, a stirring rate of $50 \mathrm{rpm}$ was applied to simulate the buccal cavity environment. The time required for the formulation to erode completely was recorded.

\section{In vitro drug release study}

Total immersion method was used to study the release behavior of KET from EL-NF and ES-NF. ${ }^{19}$ NFs and solventcasted films were cut into pieces containing $25 \mathrm{mg}$ of KET, and each was placed into a beaker filled with $50 \mathrm{~mL}$ phosphate buffer ( $\mathrm{pH}$ 6.8), which was covered and placed in a horizontal shaking water bath (WiseCube ${ }^{\circledR}$; DAIHAN, Seoul, Korea) at 50 shakes $/ \mathrm{min}$ and $37^{\circ} \mathrm{C} \pm 0.5^{\circ} \mathrm{C}$. At predetermined time intervals, an aliquot of $0.5 \mathrm{~mL}$ was withdrawn and replaced by fresh pre-warmed buffer solution. The samples were filtered and analyzed spectrophotometrically at $\lambda_{\max } 260 \mathrm{~nm}$. The cumulative percent of KET released was calculated by dividing the amount of KET released by the total amount of KET loaded in the NFs. These values were corrected for the amount of KET removed at each time. ${ }^{20}$

\section{Ex vivo permeation study}

KET permeation through the chicken buccal mucosa was performed using modified Franz diffusion cells (Nan Cheng Medical Glass, Taipei, Taiwan). The receptor compartment of the cell had $21 \mathrm{~mL}$ capacity and was surrounded by water jacket to maintain the temperature at $37^{\circ} \mathrm{C} \pm 0.5^{\circ} \mathrm{C}$ with a circulating water bath. ${ }^{21}$ The fresh chicken buccal mucosa was carefully separated from underlying fat and muscles using a scalpel and stored immediately in phosphate buffer pH 6.8 at $-20^{\circ} \mathrm{C}$. Before performing the experiment, the membranes were thawed and allowed to equilibrate in receptor buffer for $\sim 1$ hour to regain the elasticity. The membranes were then mounted between the donor and receptor compartments with the mucosal layer facing the donor compartment.

NFs containing $10 \mathrm{mg}$ KET were placed on the top of the mucosa, and the two compartments were clamped together. The donor compartment was filled with $5 \mathrm{~mL}$ of isotonic phosphate buffer ( $\mathrm{pH}$ 6.8) to simulate the saliva in the mouth and to initiate the release of the drug. The receptor compartment was filled with the same buffer. The hydrodynamics in the receptor compartment was maintained by stirring with a magnetic bar at $50 \mathrm{rpm}$. A total of $1 \mathrm{~mL}$ of sample was withdrawn at predetermined time intervals and replaced with an equal volume of the same fresh and pre-warmed medium.
The drug concentrations were determined spectrophotometrically and corrected for the amount of KET removed at each time point. ${ }^{20}$

\section{In vivo animal study}

All rabbits in this study were housed in separate cages in a light-dark cycle and temperature-controlled environment and were allowed to adapt to the housing conditions for 1 week prior to the start of the experiment. Experiments were approved and performed in accordance with the guidelines of the Institutional Animal Care and Use Committee (Faculty of Pharmacy, Alexandria University).

The rabbits were fasted 2 hours prior to oral mucositis induction, which was performed under anesthesia with an intramuscular injection of $35 \mathrm{mg} / \mathrm{kg}$ ketamine and $5 \mathrm{mg} / \mathrm{kg}$ xylamine. ${ }^{22}$ To induce mucosal ulcer, $50 \%$ acetic acid-soaked cotton bud was pressed on the buccal mucosal tissue of the anesthetized rabbits for 60 seconds on both sides of the buccal cavity. ${ }^{23-25}$ After induction of mucositis, rabbits were divided into two groups containing three in each group. Rabbits in group 1 were treated by the selected formula of 20\% EL-NF loaded with $20 \%$ KET (F1), while group 2 served as oral mucositis control (nontreated group). One extra rabbit served as normal control. In the treatment group, both sides were treated with F1 containing $10 \mathrm{mg}$ KET. The treatment started on the second day after the mucositis was developed. A piece of the NFs was placed on the ulcer lesion of anesthetized rabbits and pressed firmly for a few seconds for local fixation. The anesthesia lasted for 3 hours to ensure that rabbits did not swallow the dosage form or chew on it. Treatment was applied once daily for 5 consecutive days. All rabbits were sacrificed at the end of the sixth day, and the buccal mucosa of the ulcer region on both sides was excised for further histological examination. Rabbits of the control group were left in the normal housing conditions without treatment during the 6-day experimental period. All the animals were weighed and monitored daily. The pouch mucosa of six rabbits was everted and photographed daily for subsequent clinical evaluation. A sample of the buccal mucosa from the normal control rabbit was also excised for comparison.

\section{Histopathological study}

All freshly excised buccal mucosal samples were immediately fixed in $10 \%$ formalin solution in an amber glass bottle. Then, samples were embedded in paraffin wax and sectioned into thicknesses of $10 \mu \mathrm{m}$, which were stained with hematoxylin and eosin. The slides were evaluated under a microscope for any abnormality. The absence or presence 
of microscopically visible ulceration and severity of inflammatory infiltrate were rated using a scoring system reported by Lopez et al. ${ }^{1}$

\section{Statistical analysis}

All results were statistically analyzed by analysis of variance (ANOVA) using SPSS 17.0 software (SPSS Inc., Chicago, USA, 2007). Post hoc multiple comparisons test was applied when required. $P \leq 0.05$ indicated statistical significance values. Body weight loss data were analyzed by Student's $t$-test with significance level set at 5\%.

\section{Results and discussion Optimization of preparation of EL-NF and ES-NF}

Four different factors namely polymer concentration, applied voltage, flow rate and drug concentration were examined to optimize NF production using EL and ES polymers.

\section{Effects of polymer concentration}

Different concentrations (10, 15, 20 and 25\% w/v) of EL and

ES ethanolic solutions were electrospun at a fixed feeding rate of $0.5 \mathrm{~mL} / \mathrm{h}$, and the applied voltage was $15 \mathrm{kV}$. SEM examination showed drastic morphological changes when the concentration of polymer solutions changed (Figure 1). When EL and ES concentrations were as low as 10\% (w/v), many beads appeared in the electrospun products (Figure 1AI and AII, respectively). Increasing the polymer concentration to $15 \%(\mathrm{w} / \mathrm{v})$ decreased the number and size of beads in the case of EL (Figure 1BI); however, ES showed a lot of defects in the form of beads and fusion points (Figure 1BII). Further increase in the concentrations to $20 \%$ and $25 \%$ resulted in bead disappearance and uniform smooth fiber formation in EL and ES (Figure 1CI, DI, DII and CII). However, the viscosity of polymer solutions was very high at the polymer concentration $25 \%(\mathrm{w} / \mathrm{v})$, resulting in the frequent clogging of the needle. As a result, the droplet dried out at the tip before jets could be initiated, disturbing the jet flow and leading to a constant need to remove the clog to allow the electrospinning process to continue.

It was important to investigate the rheological properties of polymer solutions used in electrospinning because they can have substantial effects on the electrospinning process as well as the quality and morphology of fibers produced. ${ }^{26}$ The relationship between EL and ES concentrations (10, 15 and $20 \% \mathrm{w} / \mathrm{v}$ ) and the corresponding solution viscosity are presented in Figure 2, which demonstrated that viscosity of EL and ES solutions was significantly increased by increasing the polymer concentration from $10 \%$ to $20 \%$ (w/v; $P \leq 0.001)$.

The rheological studies could explain the formation of beads. At low concentration, the viscosity of the polymer solution was low and the surface tension became the dominant factor in the electrospinning process, which tended to make the surface area per unit mass smaller by changing the jet into spheres or beads. ${ }^{27}$ By increasing the concentration, the viscosity of the polymer solution increased and the jet would be less likely to break up because of the greater viscoelastic forces. The formed filaments between the droplets were more stabilized, and a mixture of beads and fibers was obtained (Figure 1A and B). When the polymer solution increased to a suitable concentration, smooth, fine NFs could be obtained due to the high viscoelastic forces, which resisted the formation of beads (Figure 1C and D). Our results were consistent with Zong et $\mathrm{al}^{28}{ }^{28}$ Buchko et $\mathrm{al}^{29}$ and Fong et $\mathrm{al}^{30}$ who also found that higher polymer concentrations resulted in fibers with fewer beads.

It is worth mentioning that a linear relationship was observed between the plot of shear stress and shear rate of $20 \%(\mathrm{w} / \mathrm{v}) \mathrm{ES}\left(r^{2}=0.99\right)$ and $\mathrm{EL}\left(r^{2}=0.99\right)$ solutions, where the increase in shear rate was directly proportional to the increase in average shear stress, suggesting Newtonian behavior of these two polymer solutions, which was advantageous under the condition of electrospinning process. Our results also agreed with the reported data stating that Eudragit solution showed Newtonian behavior at low shears. ${ }^{31}$ To study the effects of polymer concentration on NF diameter, the produced electrospun NF diameters were measured by SEM image analysis software. Table 1 lists the relationship between the polymer concentration and their corresponding NF diameter, which increased significantly $(P \leq 0.001)$ by increasing EL and ES concentrations.

A number of researchers studied the relationship between the concentration and NF diameter using various polymers, including polyethylene oxide ${ }^{32}$ and acrylonitrile. ${ }^{33}$ They concluded that a higher concentration and viscosity resulted in a larger NF diameter.

The equations that correlated the NF diameter to polymer concentration were $\mathrm{Y}=0.269 \mathrm{X}^{2.256}$ and $\mathrm{Y}=0.89 \mathrm{X}^{2.849}$, for EL-NF and ES-NF, respectively, where $\mathrm{Y}$ was the NF diameter and $\mathrm{X}$ was the polymer solution concentration. The coefficient of determination $R^{2}$ was found to be 0.8 and 0.848 for EL-NF and ES-NF, respectively. Our results were similar to that obtained by $\mathrm{Ki}$ et $\mathrm{al}^{34}$ who reported that the relation between the NF diameters and polymer concentrations of both EL-NF and ES-NF followed the power law relationship. 

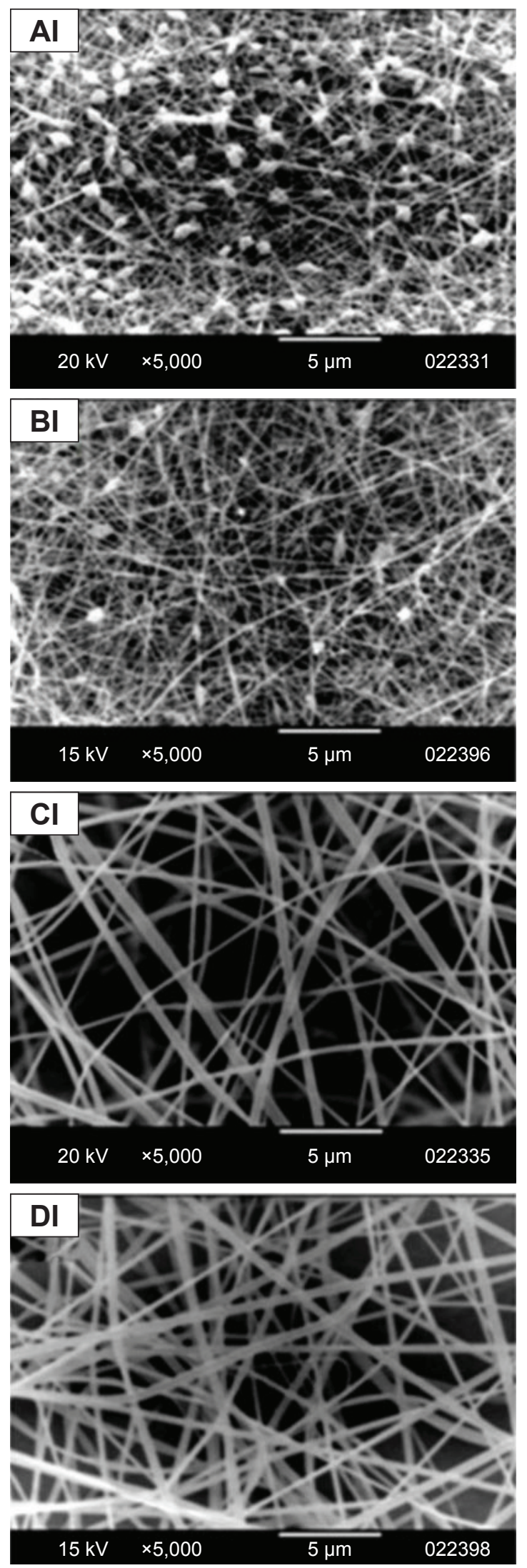
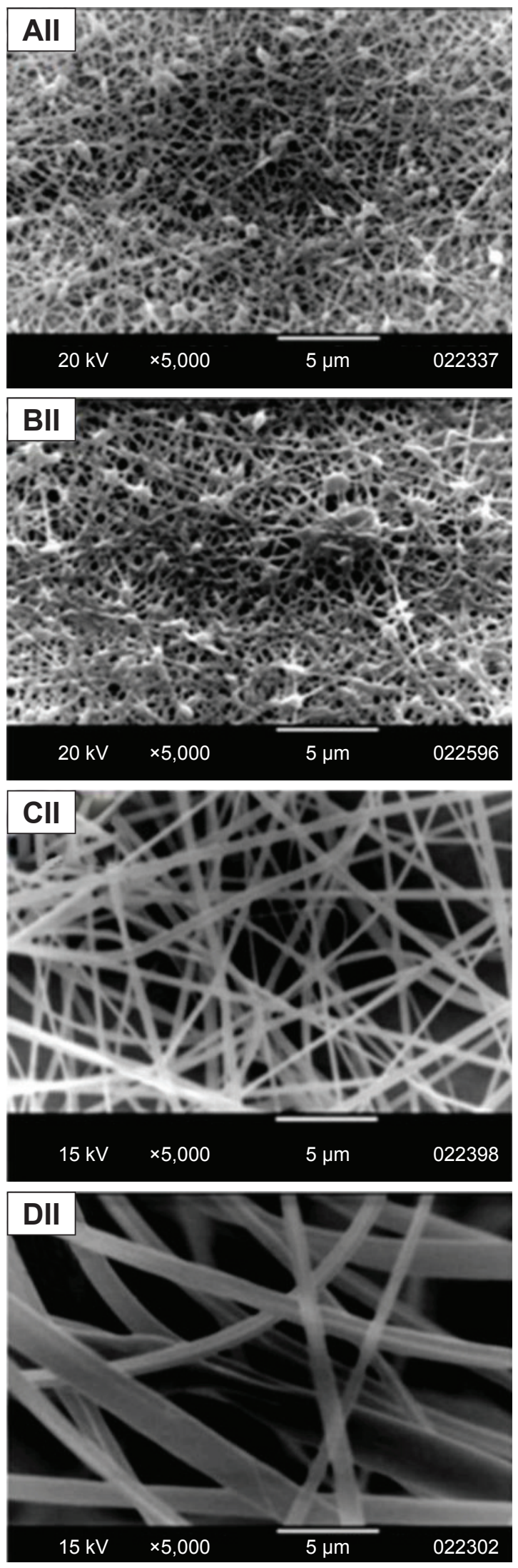

Figure I SEM micrographs of EL (I) and ES (II) blank NFs prepared using different concentrations, (A) $10 \%$, (B) 15\%, (C) 20\% and (D) $25 \%$, and electrospun at I5 kV and at $0.5 \mathrm{~mL} / \mathrm{h}$ flow rate (magnification power $\times 5,000$ )

Abbreviations: SEM, scanning electron microscopy; EL, Eudragit LI00; ES, Eudragit SI00; NF, nanofiber. 


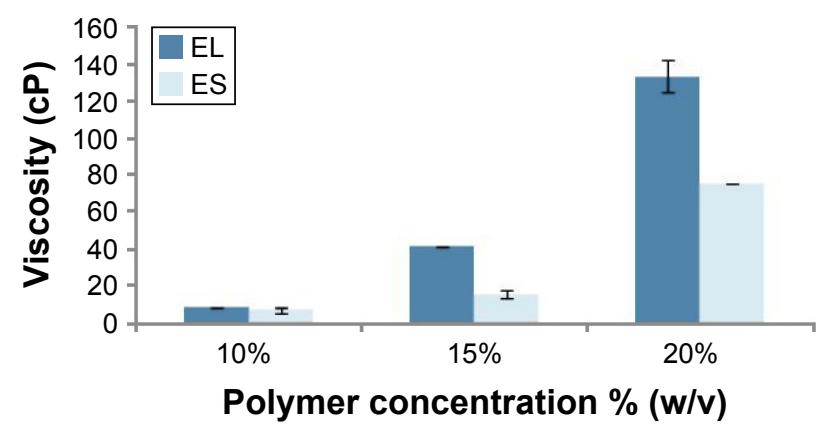

Figure 2 Effects of different concentrations (10, 15 and 20\%) of EL and ES on the viscosity of polymer solution, measured at room temperature at $180 \mathrm{rpm}$. Abbreviations: EL, Eudragit LI00; ES, Eudragit SI00.

From the previous results, the polymer concentration of $20 \%(\mathrm{w} / \mathrm{v})$ for ES and EL was selected as it produced smooth fibers with no beads and showed less clogging in the spinneret.

\section{Effects of applied voltage}

Different voltages $(10,15,20$ and $25 \mathrm{kV})$ were applied on $15 \%(\mathrm{w} / \mathrm{v})$ EL solutions to investigate the effects of the applied voltage on the process of electrospinning, NF diameter and bead formation. Since EL-NF prepared at the polymer concentration of $15 \%(\mathrm{w} / \mathrm{v})$ showed some beads, a trial was performed to improve the morphology of the prepared NFs using the least possible concentration of polymer (15\%) by changing the applied voltage. The results revealed that application of higher voltages resulted in a highly significant increase $(P \leq 0.001)$ in the resultant NF diameter (Table 2). The possible explanation of the increase in diameter as a function of the applied voltage could be as follows: when the voltage increased, the volume of the drop at the tip decreased, causing Taylor cone to recede, which increased the amount of fluid ejected and increased the flow of polymer solution, resulting in larger fiber diameter. ${ }^{35}$ However, the correlation between NF diameter and voltage was ambiguous in the literature. For example, Reneker and $\mathrm{Chun}^{36}$ have

Table I Effects of different concentrations of EL and ES on the diameter of blank NFs

\begin{tabular}{lll}
\hline $\begin{array}{l}\text { Polymer } \\
\text { concentration (\%) }\end{array}$ & $\begin{array}{l}\text { EL-NF diameter } \\
(\mathbf{n m}) \pm \mathbf{S D}\end{array}$ & $\begin{array}{l}\text { ES-NF diameter } \\
(\mathbf{n m}) \pm \text { SD }\end{array}$ \\
\hline 10 & $51.2^{\mathrm{d}} \pm 22.7$ & $69.7^{\mathrm{d}} \pm 24.8$ \\
15 & $124.4^{\mathrm{c}} \pm 50.3$ & $171.4^{\mathrm{c}} \pm 37.2$ \\
20 & $295.2^{\mathrm{b}} \pm 91.2$ & $590.4^{\mathrm{b}} \pm 156.2$ \\
25 & $355.7^{\mathrm{a}} \pm 117.2$ & $864.4^{\mathrm{a}} \pm 371.8$ \\
\hline
\end{tabular}

Notes: The feeding rate was $0.5 \mathrm{~mL} / \mathrm{h}$ at an applied voltage of $15 \mathrm{kV} . \mathrm{a}>\mathrm{b}>\mathrm{c}>\mathrm{d}$. Abbreviations: EL, Eudragit LI00; ES, Eudragit SI00; NF, nanofiber; SD, standard deviation.
Table 2 Effects of applied voltage on the diameter of 15\% (w/v) blank EL-NF

\begin{tabular}{ll}
\hline Applied voltage $(\mathbf{k V})$ & Diameter $(\mathbf{n m}) \pm \mathbf{S D}$ \\
\hline 25 & $186.43^{\mathrm{a}} \pm 51.01$ \\
20 & $182.75^{\mathrm{a}} \pm 62.60$ \\
15 & $125.58^{\mathrm{b}} \pm 33.19$ \\
10 & $123.91^{\mathrm{b}} \pm 48.35$ \\
\hline
\end{tabular}

Notes: The feeding rate was $0.5 \mathrm{~mL} / \mathrm{h} . \mathrm{a}>\mathrm{b}$.

Abbreviations: EL, Eudragit LI00; NF, nanofiber; SD, standard deviation.

demonstrated that there was not much effect of electric field on the diameter of electrospun polyethylene oxide NFs. Other studies of poly(D-lactide) ${ }^{28}$ and polyvinyl alcohol ${ }^{37}$ showed that higher voltages yielded larger fiber diameters; however, when spinning silk-like polymer, ${ }^{29}$ the NF diameter decreased by increasing the applied voltage due to a higher degree of jet stretching by increasing the applied voltage.

Kanani and $\mathrm{Bahrami}^{38}$ showed that by increasing the voltage, the diameter of polycaprolactone NFs increased when the polymer was dissolved in solvents such as glacial acetic acid and glacial formic acid. However, this increase was not significant in the case of polycaprolactone dissolved in acetic acid as a solvent. It is worth mentioning that varying the applied voltage did not solve the problem of bead formation as shown in SE micrographs (Figure 3).

From the previous results, it could be concluded that varying the voltage did not improve the problem of bead formation using the polymer solution of $15 \%(\mathrm{w} / \mathrm{v}) \mathrm{EL}$. Therefore, the polymer solution of $15 \%(\mathrm{w} / \mathrm{v})$ was eliminated and $20 \%$ $(w / v)$ EL was used instead for further investigations.

The optimum selected applied voltage for EL 20\% (w/v) was $15 \mathrm{kV}$, as from the visual inspection, the flow of NF jet produced at $10 \mathrm{kV}$ was irregular and frequently interrupted. On the other hand, the NF flow produced at $15 \mathrm{kV}$ was more regular and continuous.

\section{Effects of flow rate}

The effects of different flow rates on the NFs prepared using 20\% (w/v) EL and ES solutions were investigated in an attempt to reduce the time necessary for the production of NFs. In general, a minimum flow rate of the polymer is required in order to replace the solution that is lost when the NF jet is ejected, as the polymer solution will have enough time for polarization, stretching and drying. ${ }^{33}$ Smooth, fine NFs were formed at a low flow rate of $0.5 \mathrm{~mL} / \mathrm{h}$ (Figure 4AI and II); however, fiber diameter became larger and fusion points appeared when the flow rate increased to $1 \mathrm{~mL} / \mathrm{h}$ (Figure 4BI and II). At higher flow rates $(2 \mathrm{~mL} / \mathrm{h})$, 

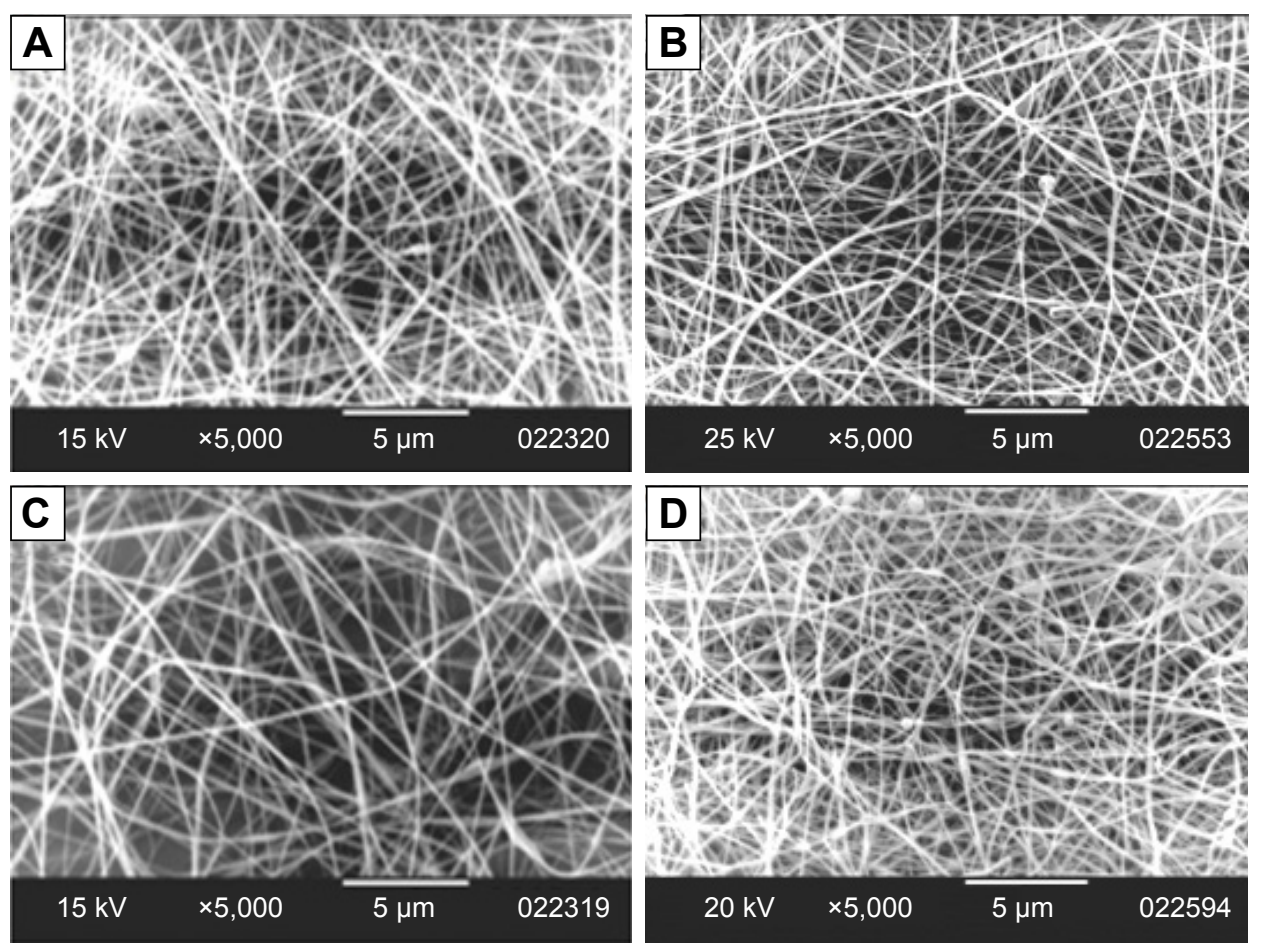

Figure 3 SEM micrographs of blank EL I5\% (w/v) NFs prepared at different voltages: (A) 10 kV, (B) 15 kV, (C) 20 kV and (D) 25 kV.

Note: The feeding rate was fixed at $0.5 \mathrm{~mL} / \mathrm{h}$.

Abbreviations: SEM, scanning electron microscopy; EL, Eudragit LI00; NF, nanofiber.

fibers did not have a chance to dry prior to reaching the collector; therefore, fusion points and structural deformations were observed in SEM results. Zong et $\mathrm{al}^{28}$ reported that at a higher flow rate, the available polymer solution volume was high; therefore, the droplet suspended at the end of the spinneret was larger; the jet of the solution carried the fluid away with a faster velocity and trajectory. Consequently, the electrospun fibers were not completely dry before reaching the collector. This resulted in larger beads, junctions of the fiber mat and larger fiber diameters. ${ }^{27,28}$ One should also consider that electric current might also be affected by the flow rate. Theron et $\mathrm{al}^{39}$ studied the effects of solution flow rate on electric current and surface charge density. They found that by increasing the flow rate, the electric current increased and the surface charge density decreased.

From the previous results, $0.5 \mathrm{~mL} / \mathrm{h}$ was selected as an optimum polymer solution flow rate under the current experimental conditions.

\section{Effects of KET-loading concentration}

The addition of KET at concentrations of $10 \%, 15 \%$ and $20 \%$ (w/v) to $20 \%(\mathrm{w} / \mathrm{v})$ EL produced smooth NF mats prepared at a flow rate of $0.5 \mathrm{~mL} / \mathrm{h}$ and at $15 \mathrm{kV}$ (Figure 5).

On the other hand, only $20 \%(\mathrm{w} / \mathrm{v})$ ES-NF loaded with $10 \%(\mathrm{w} / \mathrm{v})$ KET produced smooth NFs under the same experimental conditions (Figure 6). However, the increase in the drug concentration to 15 and $20 \%(\mathrm{w} / \mathrm{v})$ caused the produced ES-NF to be very brittle and difficult to be removed from the collector. However, EL-NF and ES-NF containing various concentrations of KET showed no fusion points or structural deformations in SEM pictures and no drug crystals or aggregates were observed.

The reason for the fragile morphology of ES-NF loaded with a high concentration of KET could be due to the high volatilization rate of solvent and the significant decrease in viscosity after addition of KET $(P \leq 0.001)$. Therefore, polymer jet did not have enough chain entanglements and the time was not sufficient for jet orientation before solvent evaporation due to the high speed of spinning as reported by Kanani and Bahrami. ${ }^{38}$

Zeng et $\mathrm{al}^{40}$ demonstrated that the solubility and compatibility of the drug in the drug-polymer-solvent system were important factors in the morphology of NFs produced. In this study, both KET and the polymers were soluble in ethanol, which explained their compatibility and the compatibility of the homogeneous fibers produced where no phase separation occurred.

By increasing the drug loading, the fiber diameter decreased significantly $(P \leq 0.001)$ in the case of ES-NF and EL-NF (Table 3). This phenomenon was probably due to the 

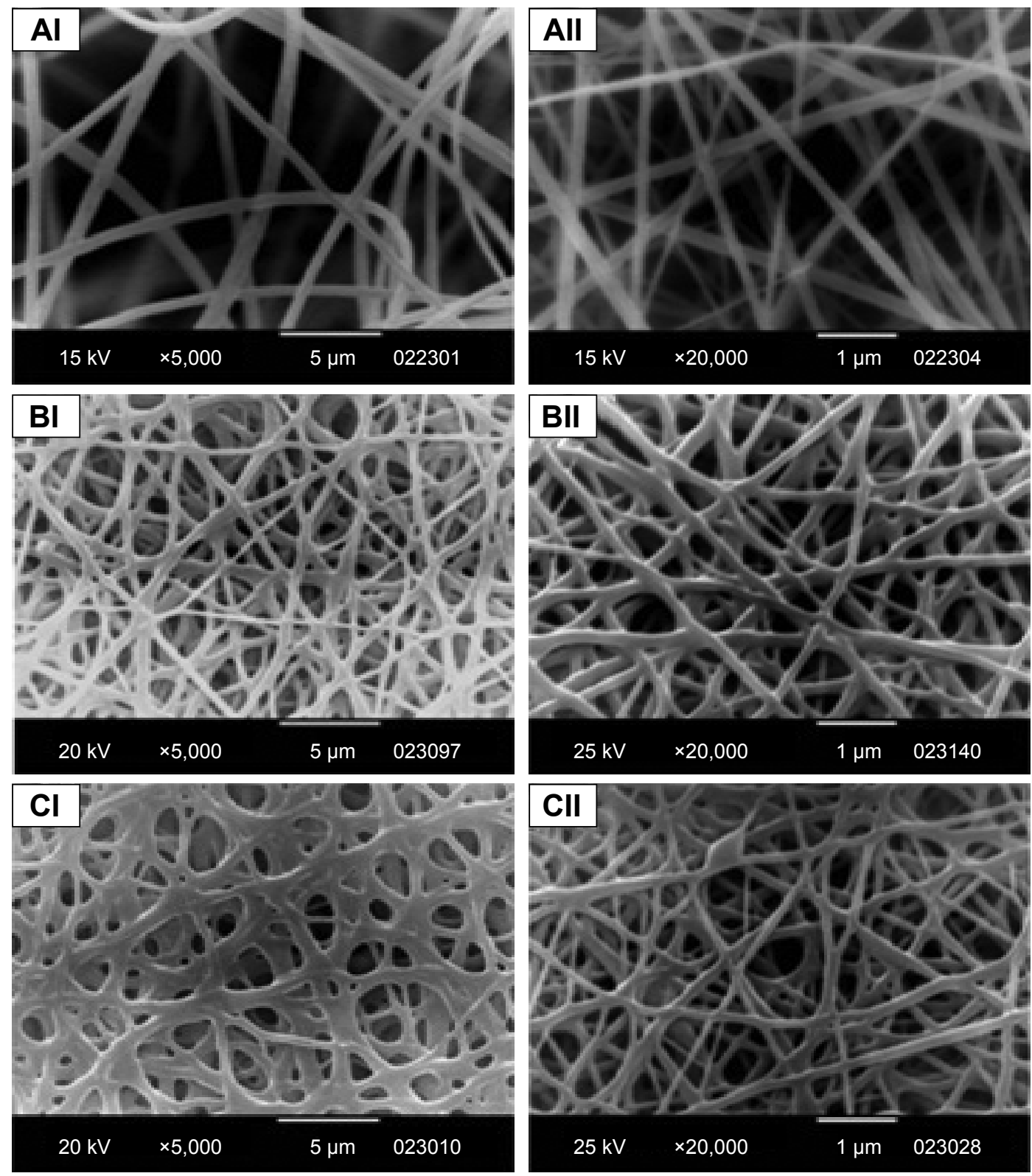

Figure 4 SEM micrographs of blank 20\% (w/v) EL (I) and ES (II) NFs prepared at different flow rates: (A) $0.5 \mathrm{~mL} / \mathrm{h}$, (B) I mL/h and (C) $2 \mathrm{~mL} / \mathrm{h}$. Abbreviations: SEM, scanning electron microscopy; EL, Eudragit LI00; ES, Eudragit SI00; NF, nanofiber.

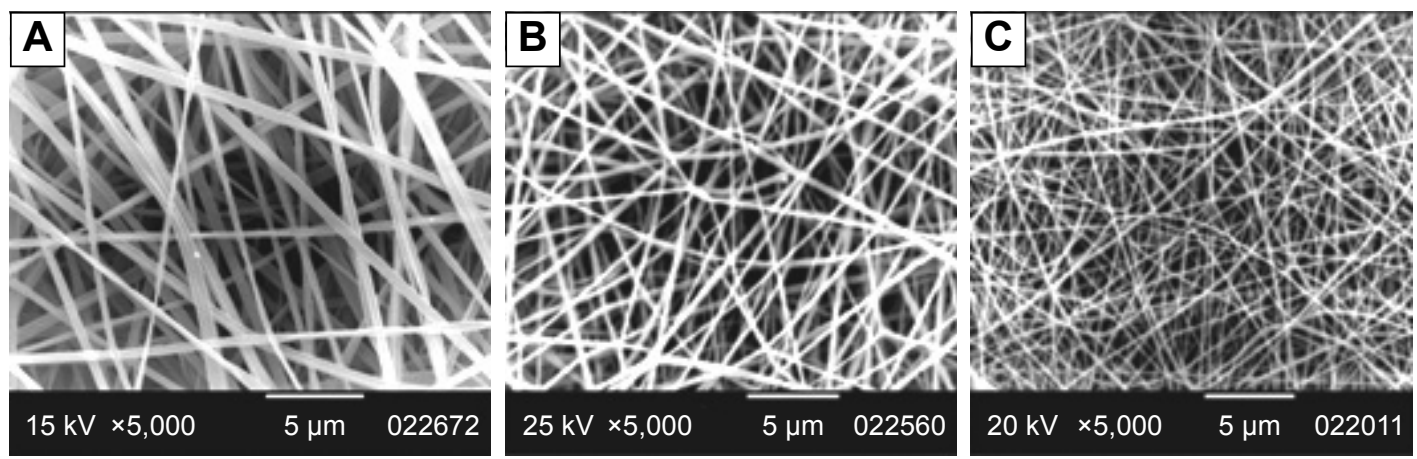

Figure 5 SEM micrographs of 20\% (w/v) EL-NF with different loaded KET concentrations, (A) 10\%, (B) $15 \%$ and (C) $20 \%(\mathrm{w} / \mathrm{v})$, produced at a flow rate of $0.5 \mathrm{~mL} / \mathrm{h}$ and an applied voltage of $15 \mathrm{kV}$.

Abbreviations: SEM, scanning electron microscopy; EL, Eudragit LI00; NF, nanofiber; KET, ketoprofen. 

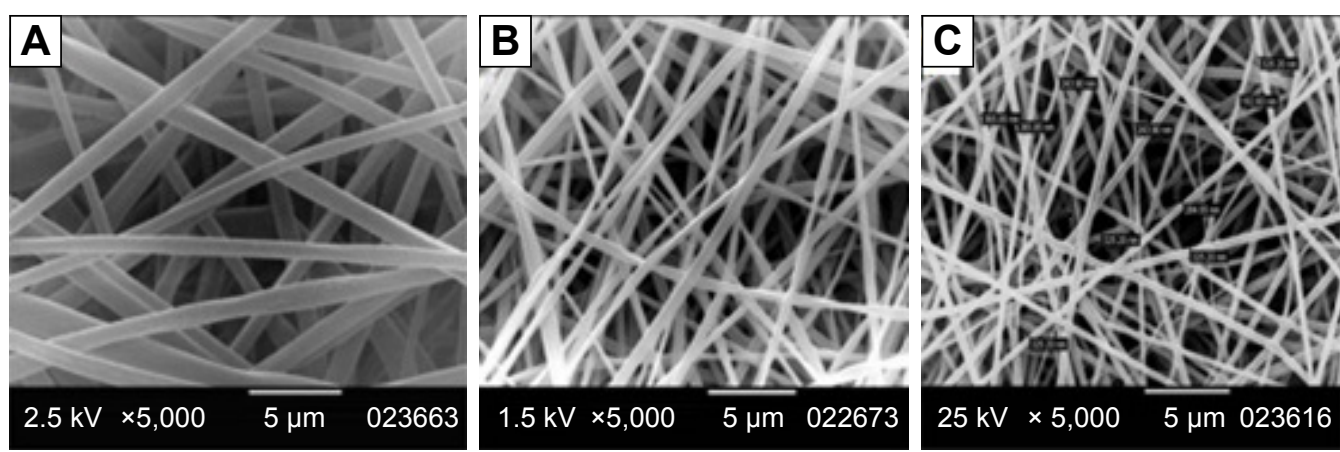

Figure 6 SEM micrographs of $20 \%$ (w/v) ES-NF with different loaded KET concentrations, (A) $10 \%$, (B) $15 \%$ and (C) $20 \%$ (w/v), produced at a flow rate of $0.5 \mathrm{~mL} / \mathrm{h}$ and an applied voltage of $15 \mathrm{kV}$.

Abbreviations: SEM, scanning electron microscopy; ES, Eudragit SI00; NF, nanofiber; KET, ketoprofen.

significant decrease in viscosity of both solutions after adding the drug (Table 3), which reduced the mean average diameter of the produced NFs. The decrease in fiber diameter might be also due to the increased stretching during electrospinning due to the increased electrical conductivity and charge density of the solution, leading to more elongation of the jet. ${ }^{35}$ Similar results were also reported in the literature. ${ }^{41-43}$

From the previous optimization results, two optimum NF formulations were selected. The first one was composed of $20 \%$ (w/v) EL-NF loaded with 20\% (w/v) KET and was coded as F1. The second one was $20 \%$ (w/v) ES-NF loaded with $10 \%(w / v)$ KET and was coded as F2. They were selected for further investigations as they had acceptable diameters with no beads or fusion points. They also demonstrated the highest theoretical drug loading with no effect on NF morphology. Both formulae were electrospun at a feeding rate of $0.5 \mathrm{~mL} / \mathrm{h}$ and an applied voltage of $15 \mathrm{kV}$.

\section{Evaluation of the selected electrospun NFs Drug loading}

The entrapment efficiency was $93.1 \% \pm 3.2 \%(\mathrm{w} / \mathrm{w})$ for $\mathrm{F} 1$ and $90.2 \% \pm 4.3 \%(\mathrm{w} / \mathrm{w})$ for F2. High entrapment efficacy

Table 3 Effects of different KET concentrations on the diameter of NFs

\begin{tabular}{lll}
\hline NF formulation & $\begin{array}{l}\text { Viscosity } \\
(\mathbf{c P})\end{array}$ & $\begin{array}{l}\text { Mean diameter } \\
(\mathbf{n m}) \pm \text { SD }\end{array}$ \\
\hline ES 20\%+0\% KET & 78 & $590.4^{\mathrm{a}} \pm 24.8$ \\
ES 20\%+10\% KET & 60 & $499.6^{\mathrm{b}} \pm 104.9$ \\
ES 20\%+15\% KET & - & $467.3^{\mathrm{b}} \pm 139.9$ \\
ES 20\%+20\% KET & 56 & $302.3^{\mathrm{c}} \pm 58.8$ \\
EL 20\%+0\% KET & 130 & $295.2^{\mathrm{a}} \pm 91.2$ \\
EL 20\%+10\% KET & 98 & $286.7^{\mathrm{a},} \pm 86.0$ \\
EL 20\%+15\% KET & - & $243.0^{\mathrm{b}} \pm 36.6$ \\
EL 20\%+20\% KET & 80 & $191.2^{\mathrm{c}} \pm 48.0$ \\
\hline
\end{tabular}

Notes: The feeding rate was $0.5 \mathrm{~mL} / \mathrm{h}$ at an applied voltage of $15 \mathrm{kV} . \mathrm{a}>\mathrm{b}>\mathrm{c}$. Abbreviations: KET, ketoprofen; NF, nanofiber; SD, standard deviation; ES, Eudragit SIO0; EL, Eudragit LI00. was expected due to the exceptional high surface area of the NFs and also due to the passive drug loading technique, which involved the incorporation of drug into the polymeric solution to be spun and solidified during the electrospinning process. The drug was entrapped in the polymer fiber mat; thus, the risk of drug loss during this process was low. The resulted high entrapment efficiency allowed significant flexibility to reduce the size of NF mats for buccal administration, making self-administration convenient for patients.

The actual drug loading was $46.5 \% \pm 1.6 \%(\mathrm{w} / \mathrm{w})$ and $30 \% \pm 1.4 \%(\mathrm{w} / \mathrm{w})$ for $\mathrm{F} 1$ and $\mathrm{F} 2$, respectively. The theoretical drug loading in the case of EL-NF (F1) was $50 \%(\mathrm{w} / \mathrm{w})$ and $33.3 \%(\mathrm{w} / \mathrm{w})$ in the case of ES-NF (F2). The achieved drug loading in the case of EL was higher than the published data, where it did not exceed $37.5 \%(\mathrm{w} / \mathrm{w}) .{ }^{13}$

\section{DSC}

DSC examinations were conducted for the pure drug, the polymers and the two different formulations $\mathrm{F} 1$ and $\mathrm{F} 2$ as shown in Figure 7.

The thermogram of the pure KET exhibited only one sharp endothermic peak at $95^{\circ} \mathrm{C}$ corresponding to its melting point $\left(T_{\mathrm{m}}\right)$, indicating its presence in the crystalline state (same as reported by El-Kamel et $\mathrm{al}^{44}$ ). For pure EL, there was a broad endotherm between $50^{\circ} \mathrm{C}$ and $110^{\circ} \mathrm{C}$ due to dehydration and a second one ranging from $195^{\circ} \mathrm{C}$ to $219^{\circ} \mathrm{C}$, which may be due to thermal degradation. These findings were consistent with other results documented by Illangakoon et al. ${ }^{45} \mathrm{ES}$ exhibited broad glass transition (Tg) endothermic peaks at $90^{\circ} \mathrm{C}$ and $230^{\circ} \mathrm{C}$ as reported by Karthikeyan et al. ${ }^{16}$ These data confirmed that both ES and EL are amorphous as reported previously.

The endothermic peak due to fusion of drug crystals at $95^{\circ} \mathrm{C}$ disappeared in $\mathrm{F} 2$, suggesting an amorphous composite was formed and proving the molecular dispersion of KET 


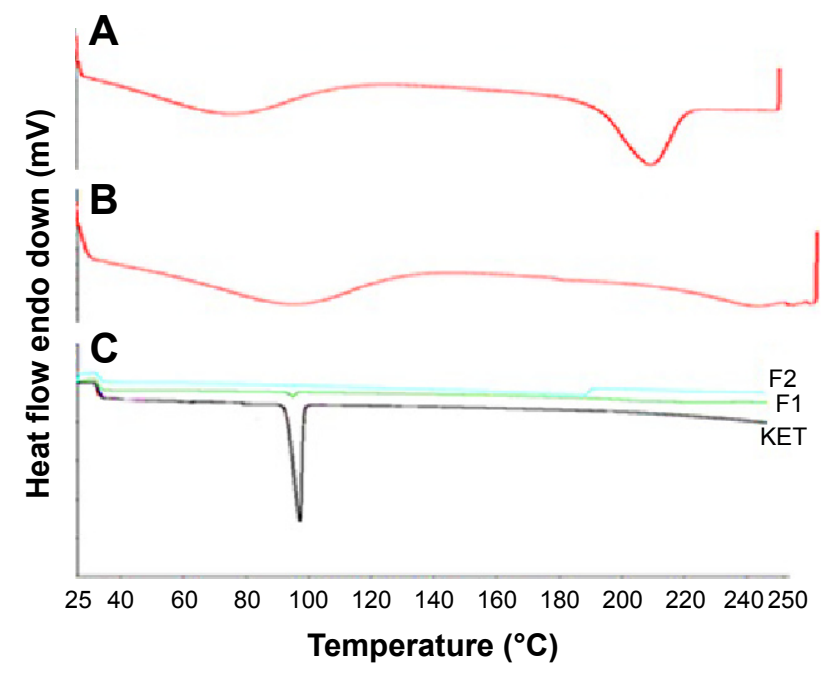

Figure 7 DSC thermogram of (A) pure EL and (B) pure ES and (C) collective DSC thermogram of KET: pure KET, FI: EL-NF and F2: ES-NF.

Abbreviations: DSC, differential scanning calorimetry; EL, Eudragit LI00; ES, Eudragit SI00; KET, ketoprofen; NF, nanofiber.

in the electrospun fiber matrix with a change in the state of drug from crystalline to amorphous. This may be due to the extremely rapid evaporation of the solvent from the fibers during the electrospinning process, causing the inability of the drug molecules to form crystalline aggregates or lattice within the NFs. ${ }^{19}$ Yet, in F1 NFs containing higher KET concentration $(20 \%)$, there was a very small endothermic peak at $95^{\circ} \mathrm{C}$, indicating very little of the drug was in the crystalline state. However, SEM images did not show any visible drug crystals on the surface of NFs. Similar results were also reported by Potrč et a ${ }^{13}$ where a small amount of ibuprofen was found in the crystalline state but did not appear in SEM images.

\section{FTIR}

Infrared (IR) spectra of pure KET, ES, EL and formulations $\mathrm{FI}$ and $\mathrm{F} 2$

Two well-defined, sharp peaks were visible for pure KET, one at $1,697 \mathrm{~cm}^{-1}$ that represented the stretching vibration carbonyl group of KET dimer and another one at $1,655 \mathrm{~cm}^{-1}$ due to the stretching of the ketone group. FTIR spectrum of pure EL displayed characteristic bands of methyl and methylene $\mathrm{C}-\mathrm{H}$ stretch vibrations at $2,993 \mathrm{~cm}^{-1}$ and a strong band of esterified carbonyl groups at $1,716 \mathrm{~cm}^{-1}(\mathrm{C}=\mathrm{O}$ stretch $)$. The shifting of the band to be at $1,716 \mathrm{~cm}^{-1}$ instead of being in the range of $1,735-1,750 \mathrm{~cm}^{-1}$ indicated hydrogen bond formation between polymer molecules. There were another two bands of ester vibration (C-O-C stretches) at 1,256 and $1,195 \mathrm{~cm}^{-1}$ and broad absorption band of $\mathrm{OH}$ group at 3,000-3,500 $\mathrm{cm}^{-1}$. The ES spectrum also showed the characteristic methyl and methylene $\mathrm{C}-\mathrm{H}$ stretch vibrations band at 2,999 $\mathrm{cm}^{-1}$ and a band at $1,737 \mathrm{~cm}^{-1}$ corresponding to esterified carbonyl group. Two ester vibration bands at 1,252 and $1,198 \mathrm{~cm}^{-1}$ and broad hydroxyl group absorption bands between 3,300 and $3,600 \mathrm{~cm}^{-1}$ were also observed. The ES esterified carbonyl group band was not shifted, the same as in EL, because the ratio between the free carboxyl groups to ester groups in ES was 1:2, while it was 1:1 in EL. ${ }^{46}$ Therefore, ES has lower free carboxyl group and less chance for intermolecular hydrogen bonding compared to EL.

KET molecules possess free hydroxyl groups that act as potential proton donors and carbonyl groups that serve as potential proton receptors for hydrogen bonding. Therefore, hydrogen bonding interactions can be speculated to occur within the KET-loaded EL-NF and ES-NF. The peak at $1,697 \mathrm{~cm}^{-1}$ corresponding to the stretching vibration of carbonyl group of pure KET dimers disappeared in the spectra of both F1 and F2, indicating the breakage of KET dimers and formation of hydrogen bonding between the polymer and KET molecules. Thus, by interacting with the polymer, KET molecules were less likely to form dimers essential for crystal lattice formation. ${ }^{46}$ The esterified carbonyl stretching band characteristic of EL in F1 was shifted to $1,728 \mathrm{~cm}^{-1}$, which may also be due to intermolecular hydrogen bond formation between KET and EL molecules.

Furthermore, the disappearance of the stretching vibration of ketone group at $1,658 \mathrm{~cm}^{-1}$ in pure KET indicated hydrogen bond formation between the drug and polymer. ${ }^{47}$ In addition, a shift occurred to $1,727 \mathrm{~cm}^{-1}$, indicating intermolecular hydrogen bond between ES and KET molecules. Therefore, the hydrogen bonding interaction between the KET and EL/ES in the NFs might increase the compatibility between them, prevented KET crystallization in the fibers and stabilized the drug in an amorphous state in the NFs. These results were previously confirmed by DSC results.

\section{Surface $\mathrm{pH}$ and hydration capacity}

The surface $\mathrm{pH}$ of $\mathrm{F} 1$ and $\mathrm{F} 2$ ranged from $5.90 \pm 0.24$ to $6.02 \pm 0.24$, which indicated that both formulations maintained an acceptable $\mathrm{pH}$ in the range of human salivary $\mathrm{pH}$ from 5.6 to $7.0 .{ }^{48}$

The rate and the extent of NF hydration and swelling may affect the mucoadhesion and, consequently, the drug release from the NFs. ${ }^{49}$ The maximum hydration capacities of the optimized samples were obtained within 15 minutes for $\mathrm{F} 1$ and 30 minutes for F2. Then, the water uptake values decreased in both formulations due to erosion and dissolution of polymer matrix.

In general, the ability of polymers to absorb water is due to the presence of water soluble groups such as $-\mathrm{COOH}$ 
that formed hydrogen bond with the aqueous medium. The hydration of these groups resulted in water entry into polymer chain. EL and ES used in this study are copolymers, anionic in nature and based on methacrylic acid and methacrylic acid methyl ester. Both copolymers have free carboxylic acid group. The ratio of the free carboxyl groups to the ester groups is 1:1 in EL and 1:2 in ES; therefore, EL is more hydrophilic than ES. ${ }^{46} \mathrm{ES}$ is soluble in the $\mathrm{pH}$ range $>7$, while EL dissolves in $\mathrm{pH}>6$ due to its higher content of the carboxylic groups. ${ }^{50}$ The water uptake values of F1 and F2 were almost similar after 15 minutes; then, EL started to dissolve more quickly due to its hydrophilic property, forming channels and pores. The void volume formed was filled with the buffer, which gradually diffused into the NFs, leading to its rapid and complete erosion in 2 hours. On the other hand, F2 (ES) reached its maximum water uptake value at 30 minutes. The less hydrophilic nature of ES compared to EL resulted in the resistance of the matrix network structure, mainly hydrogen bonds, to the movement of water molecules. Thus, F2 did not show any appreciable changes in its shape and maintained the integrity of the NFs during the study period with only a small amount of NFs being dissolved in the buffer. Although F1 (EL) is more hydrophilic and expected to have higher water uptake values than F2 (ES), it showed significant lower values $(P \leq 0.05)$ due to the weight loss caused by erosion, which counterbalanced the high water uptake.

\section{Mucoadhesion test and mucoadhesion retention time}

The results of mucoadhesive study showed good mucoadhesive force of $14,046.6 \pm 1,131.6$ dyne $/ \mathrm{cm}^{2}$ in $\mathrm{F} 1$ and 13,720 \pm $1,697.4$ dyne $/ \mathrm{cm}^{2}$ in F2 with no statistically significant difference between them $(P>0.05)$.

The mucoadhesive property in the tested NFs might be due to polyanionic nature of both polymers used. The many $\mathrm{COOH}$ groups presented in their structures formed a hydrogen bond with the mucosal tissue. In addition to the large surface area of the NFs available to interact with biosurfaces, they can interact with the mucosa after fluid uptake through the presence of numerous nanometer-sized interfibrillar pores causing mucoadhesion. ${ }^{51}$ Gowthamarajan et $\mathrm{al}^{52}$ reported that the mucoadhesive property of polymers was influenced by their swelling nature. The higher water uptake might help in establishing a quicker and stronger interpenetration of polymer chains into the mucous and improved their contact time. Since the water uptake by EL-NF and ES-NF after 15 minutes (the time required to measure the mucoadhesive force) was almost the same, the determined adhesion force for both NFs was statistically insignificant $(P>0.05)$.

Mucoadhesive time for F1 was 2 hours; longer duration was recorded for F2 (5 hours), although the mucoadhesive force of them was almost the same. This could be due to the fact that EL (F1) dissolved at $\mathrm{pH}>6$ led to channel formations, resulting in the fast erosion of the NFs. ${ }^{46}$ At $\mathrm{pH}$ 6.8, ES (F2) was less soluble than EL; consequently, ES-NF remained intact and needed longer time to erode. None of the NF mats were detached from the mucosal membrane over the study period, which indicated that the mucoadhesion property of tested NFs was sufficient to retain them on the buccal mucosa.

A previous study reported that there is no relation between mucoadhesion strength and mucoadhesion time. ${ }^{53}$ However, in another study, Garg et $\mathrm{al}^{54}$ proposed that the extent of mucoadhesive strength will directly reflect the residence time of the dosage form in the target site.

\section{In vitro drug release study}

In vitro release profiles of KET from F1 and F2 and their corresponding casted films containing equivalent amounts of KET are presented in Figure 8. The amount of KET released from F1 and F2 was statistically significantly $(P \leq 0.001)$ higher than that released from the corresponding casted films. The results showed that $99.8 \%$ and $91.7 \%$ of KET was released within 2 hours from F1 and F2, respectively, while only $2.3 \%$ and $2.2 \%$ of KET was released from EL- and ES-casted films. The three-dimensional continuous nanoweb structure of the NFs and the molecular distributions of drug in them provided a tremendously large surface area for the drug to be exposed to the dissolution media. In addition, the large porosity of the NF mats facilitated the fast mass transfer of solvent and drug molecules from or to the dissolution medium. The nanoscale diameter of the NFs also contributed greatly to decrease the diffusion layer thickness for the drug

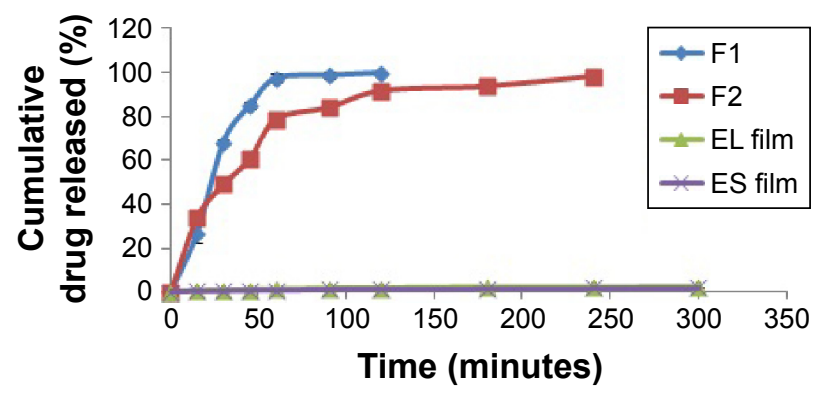

Figure 8 In vitro release profile of KET from the two selected formulas ES-NF and EL-NF and their corresponding casted films, ES and EL films, at pH $6.8(n=3)$. Note: FI, EL-NF; F2, ES-NF.

Abbreviations: KET, ketoprofen; ES, Eudragit SI00; NF, nanofiber; EL, Eudragit LI00. 
to pass through; therefore, it improved significantly the drug wettability. Furthermore, the incorporation of poorly soluble drugs such as KET in the NFs improved their release rate since electrospinning decreased the drug crystallinity, as previously demonstrated in DSC results, which confirmed the presence of KET in an amorphous state within the NFs; therefore, no crystal lattice energy had to be overcome for dissolution. The fast dissolution of the drug from NFs could augment the concentrations of supersaturated drug solution and thus correspondingly increase the drug gradients for rapid diffusion of drug molecules. ${ }^{55}$ On the other hand; the solventcasted films had very limited surface areas and porosity for quickly transferring solvent and drug molecules. Similar results have been reported in the literature comparing the drug release from NFs and films. ${ }^{28,56}$ As mentioned before, EL is more soluble in pH 6.8 than ES. After 2 hours, F1 was completely dissolved in the medium releasing all its content of KET; on the other hand, F2 still remained in the medium. This could explain the significant accelerated release of KET from $\mathrm{F} 1$ compared to $\mathrm{F} 2(P \leq 0.001)$. In clinical application, an initial fast release in the shortest time after administration is in favor of relieving the symptoms of oral mucositis. Therefore, the delivery system that can provide initial burst drug release would be desirable. In this study, an initial burst release of KET from EL-NF and ES-NF was observed due to the high surface area of NFs and the amorphous nature of KET. Therefore, they may be good candidates for rapid oromucosal drug delivery, providing high drug concentrations at the target surface and reducing the required dose.

The mechanism of drug release from the NFs was investigated using model-dependent methods. The drug release results were fitted into zero-order kinetics, first-order kinetics and Hixson-Crowell, Higuchi, Korsmeyer-Peppas and Weibull models. Based on the values of coefficient of determination $\left(R^{2}\right)$, the Weibull model was the best model fitting the release data of F1 and the Korsmeyer-Peppas model was the best model for F2 drug release $\left(R^{2}=1.00\right)$. F2 exhibited release exponent $n$ values of 0.532 , indicating that the drug release from F2 might have followed both drug diffusion and relaxation of polymeric matrix (erosion) in an anomalous non-Fickian manner. ${ }^{57}$

\section{Ex vivo permeation study}

The permeation experiment was performed for 6 hours using a chicken pouch membrane. The results (Figure 9) showed that the amount of KET permeated after 6 hours was only a small fraction (11\% for F2 and 13\% for F1) of the initial loaded amount. These results suggested that the prepared

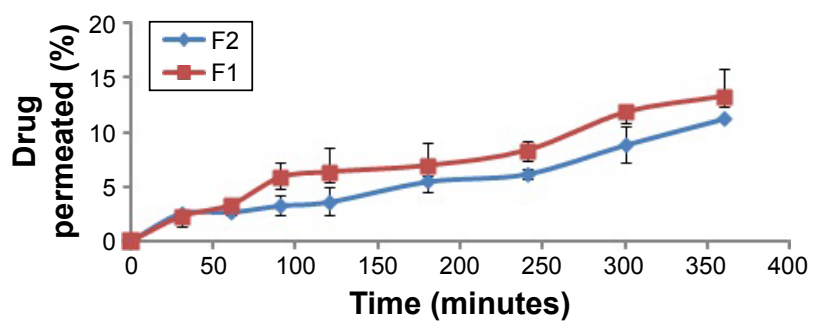

Figure 9 The permeation of KET through chicken buccal mucosa membrane from $\mathrm{FI}$ and $\mathrm{F} 2(\mathrm{n}=3)$.

Notes: FI, 20\% (w/v) EL-NF loaded with 20\% (w/v) KET; F2, $20 \%$ (w/v) ES-NF loaded with $10 \%(w / v)$ KET.

Abbreviations: KET, ketoprofen; EL, Eudragit LI00; NF, nanofiber; ES, Eudragit SI00.

formulations could be good candidates to be used for local buccal delivery with minimum drug permeation and less expected systemic absorption and side effects.

\section{In vivo animal study}

It has been reported that NFs are good candidates for wound dressing due to their high porosity, which allows exchange of gases, moisturization of the wound and drainage of exudates from the wound site. The large surface area of NFs can lead to high absorption of exudates. Sub-micron interfiber porosity on the other hand can block entry of bacteria into the wound site. Thus, nanofibrous dressings can substantially decrease the risk of wound infection. Good flexibility of the dressing and high mechanical strength are also ideal for meeting protective requirements. ${ }^{58}$

From the previous results, F1 was selected for in vivo study as it possessed a higher loading capacity than F2, thus reducing the size of the applied NF mats. Another advantage of F1 was the fast release and complete dissolution and erosion that occurred in 2 hours, which might be convenient for buccal applications in patients since there will be no need to remove the dosage form after complete drug release.

\section{Body weight analysis}

Greater weight loss was found in the oral mucositis control group due to the progressive decrease in food intake, which might be attributed to difficulty in chewing and swallowing. Treatment with F1 improved the feed intake and showed a significantly $(P \leq 0.05)$ less weight loss percentage $(4.5 \%)$ starting from the 5 th day compared to that of the untreated group ( $8 \%$ ). This reflected the degree of oral mucositis in the treated group, which was almost healed by the 6th day. During the first 4 days of the study, the weight loss in both groups was statistically insignificant $(P>0.05)$ when comparing the treated and untreated groups. The reason for the weight loss in the treated group was probably due to the more frequent 
handling of the animals than in those of the mucositis control group. In addition, the daily intramuscular anesthetic injection to prevent swallowing of the NFs might also provoke greater stress and discomfort to these animals.

\section{Clinical evaluation of oral mucositis}

Normal pouch mucosa (Figure 10A) showed intact epithelial lining with no areas of hyperemia, bleeding or ulcerations.

On the same day after induction of oral mucositis, rabbits from both groups showed inflammatory changes manifested as increased erythema and hyperemia with interruption of the normal epithelial lining, presence of hemorrhagic areas and extensive ulcerations (Figure 10B). On the second day, the inflammatory manifestations continued and a white fibrous tissue was formed in both groups (Figure 10C and D) where the ulcer reached its developmental peak. ${ }^{59}$ By day 6 , there was a marked reduction in the severity of mucositis in the treated group, showing healing of ulcerations with mild
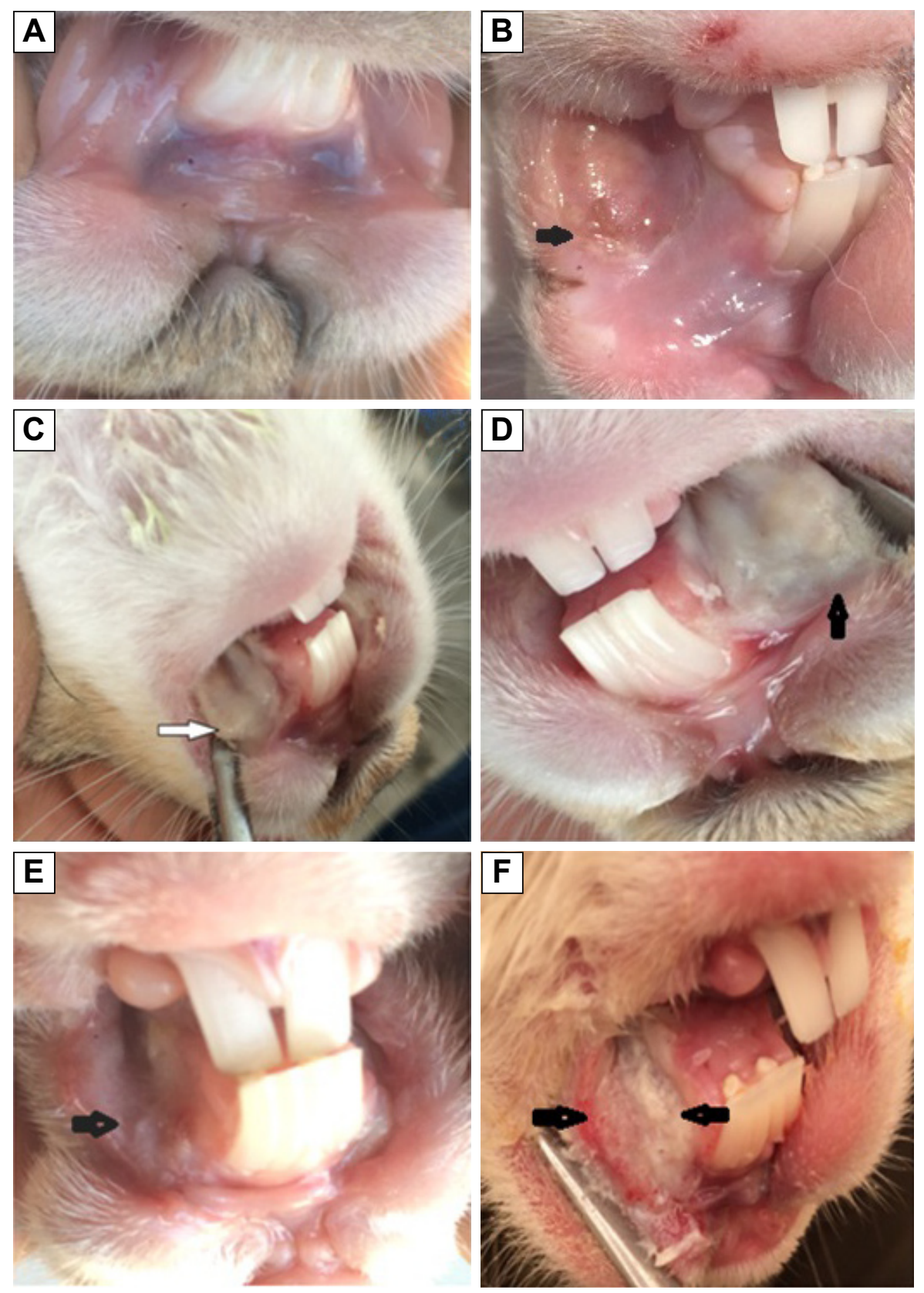

Figure 10 Photographs of rabbit mucosal pouch: (A) normal control, (B) rabbit mucosa immediately after induction, (C) treated group at day 2, (D) nontreated group at day 2, (E) treated group at day 6 and (F) nontreated group at day 6 .

Notes: Arrow in (B) indicates the presence of hemorrhagic areas and extensive ulcerations. Arrows in (C and $\mathbf{D})$ indicates white fibrous tissue where the ulcer reached its developmental peak. Arrow in (E) shows the healing of ulcerations with mild erythema and hyperemia, no hemorrhagic areas, ulcerations or abscesses. However, the mucositis severity in the control group remained the same or was slightly reduced with severe erythema and hyperemia, presence of hemorrhagic areas and ulcerations, as shown by the arrows in (F). 

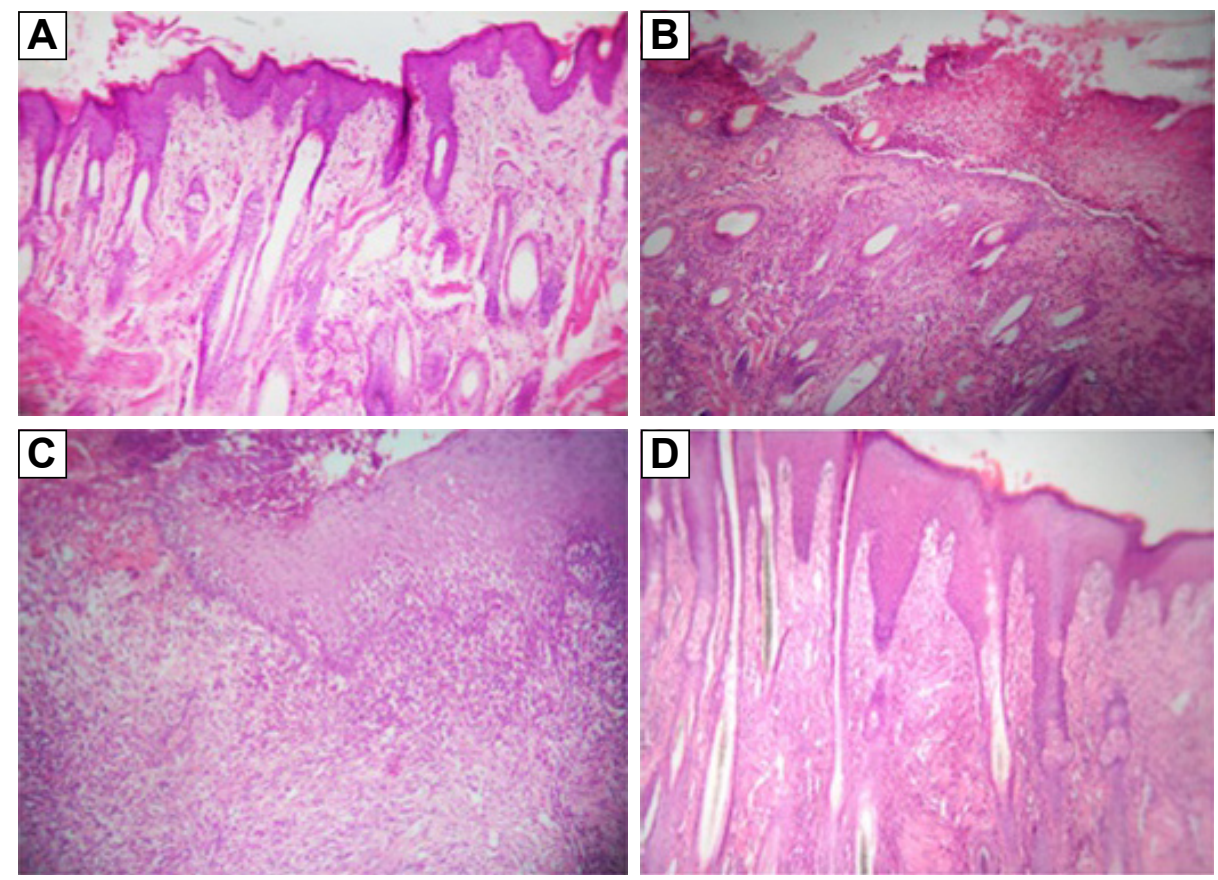

Figure I I Histopathological photographs of rabbits' buccal mucosa: (A) normal mucosa score 0, (B) score 3, (C) score 2 and (D) score I (H\&E stain $\times$ I 00). Abbreviation: H\&E, hematoxylin and eosin.

erythema and hyperemia, no hemorrhagic areas, ulcerations or abscesses (Figure 10E). However, the mucositis severity in the control group remained the same or was slightly reduced with severe erythema and hyperemia, presence of hemorrhagic areas and ulcerations, as shown in Figure 10F.

\section{Histopathological study}

Histopathological findings revealed that the excised mucosa of the normal control rabbit showed intact epithelium, with neither lymphocytic infiltration nor hyperemia, and the average score was zero (Figure 11A). At day 2, the six rabbits from both groups showed severe ulceration and dense inflammatory infiltrate involving the connective tissue on background of severe hyperemia and vasodilatation, which was given an average score 3 (Figure 11B). At day 6, ulceration was the predominant histopathological finding observed in the nontreated group, associated with moderate-to-dense inflammatory infiltrates in the connective tissue with areas of hyperemia, which indicated the presence of oral mucositis (Figure 11C). The score ranged from 2 to 3 with a mean score of $2.5 \pm 0.5$. These findings were consistent with histopathological results reported in the literature. ${ }^{60}$ The results of the treated group at day 6 showed a reduction in inflammatory changes as response to the treatment with F1 as compared to those of the nontreated group; the epithelium was intact, and no or very mild inflammatory infiltrates were present. The score ranged from 0 to 1 (Figure 11D), and a mean score of $0.8 \pm 0.3$ was recorded. Our results supported the documented role of anti-inflammatory drugs in the treatment of oral mucositis. Other than the anti-inflammatory effect of KET, the electrospun NF mats also protected the ulcer from bacterial infection where continuous re-epithelialization and shrinkage of the wound area in the treated group were observed, as a moist environment helped promote more rapid re-epithelialization. ${ }^{61}$

\section{Conclusion}

Electrospinning process could be successfully adopted to produce KET-loaded EL-NF and ES-NF that showed no beads or defects even after the addition of drug with acceptable physical characterization and drug release properties. The selected formulation F1 reduced the clinical severity of mucositis in rabbits, suppressed the inflammatory response and promoted the healing process.

\section{Acknowledgments}

The authors gratefully acknowledge Prof Dr Moataz Soliman and Dr Shaker Mabrouk of Materials Science Department, Institute of Graduate Studies and Research, Alexandria University, for allowing them to use the electrospinning apparatus. In addition, they convey their special thanks to Dr Amany Abdel Bary of the Faculty of Medicine, Alexandria University, for her help in the histopathological evaluation. 


\section{Disclosure}

The authors report no conflicts of interest in this work.

\section{References}

1. Lopez TCC, Martins MD, Pavesi VCS, et al. Effect of laser phototherapy in the prevention and treatment of chemo-induced mucositis in hamsters. Braz Oral Res. 2013;27(4):342-348.

2. Bey A, Ahmed SS, Hussain B, Devi S, Hashmi SH. Prevention and management of antineoplastic therapy induced oral mucositis. Natl $J$ Maxillofac Surg. 2010;1(2):127-134.

3. National Cancer Institute at the US National Institutes of Health [webpage on the Internet]. Oral Complications of Chemotherapy and Head/Neck Radiation. Available from: http://www.cancer.gov/ about-cancer/treatment/side-effects/mouth-throat/oral-complicationshp-pdq\#link/_323_toc. Accessed February 13, 2016.

4. Gilhotra RM, Ikram M, Srivastava S, Gilhotra N. A clinical perspective on mucoadhesive buccal drug delivery systems. J Biomed Res. 2014;28(2):81.

5. Chou CI, Shih CJ, Chen YT, et al. Adverse effects of oral nonselective and cyclooxygenase-2-selective NSAIDs on hospitalization for acute kidney injury: a nested case-control cohort study. Medicine. 2016; 95(9):e2645.

6. Srinivas M, Medaiah S, Girish S, Anil M, Pai J, Walvekar A. The effect of ketoprofen in chronic periodontitis: a clinical double-blind study. J Indian Soc Periodontol. 2011;15(3):255-259.

7. Paquette D, Fiorellini J, Martuscelli G, et al. Enantiospecific inhibition of ligature-induced periodontitis in beagles with topical (S)-ketoprofen. J Clin Periodontol. 1997;24(8):521-528.

8. Mazzarino L, Borsali R, ElenaraLemos-Senna E. Mucoadhesive films containing chitosan-coated nanoparticles: a new strategy for buccal curcumin release. J Pharm Sci. 2014;103(11):3764-3771.

9. Tang C, Guan YX, Yao SJ, Zhu ZQ. Preparation of ibuprofen-loaded chitosan films for oral mucosal drug delivery using supercritical solution impregnation. Int J Pharm. 2014;473(1-2):434-441.

10. Abdelbary GA, Aburahma MH. Oro-dental mucoadhesive proniosomal gel formulation loaded with lornoxicam for management of dental pain. J Liposome Res. 2015;25(2):107-121.

11. Hadjieva T, Cavallin-Ståhl E, Linden M, Tiberg F. Treatment of oral mucositis pain following radiation therapy for head-and-neck cancer using a bioadhesive barrier-forming lipid solution. Support Care Cancer. 2014;22(6):1557-1562.

12. Ikeuchi-Takahashi Y, Sasatsu M, Onishi H. Evaluation of matrix type mucoadhesive tablets containing indomethacin for buccal application. Int J Pharm. 2013;453(2):454-461.

13. Potrč T, Baumgartner S, Roškar R, et al. Electrospun polycaprolactone nanofibers as a potential oromucosal delivery system for poorly watersoluble drugs. Eur J Pharm Sci. 2015;75:101-113.

14. Zhou YY, Yao HC, Wang JS, Wang DL, Liu Q, Li ZJ. Greener synthesis of electrospun collagen/hydroxyapatite composite fibers with an excellent microstructure for bone tissue engineering. Int J Nanomedicine. $2015 ; 10: 3203-3215$.

15. Mohseni M, Shamloo A, Aghababaei Z, Vossoughi M, Moravvej H. Antimicrobial wound dressing containing silver sulfadiazine with high biocompatibility: in vitro study. Artif Organs. 2016;40(8): 765-773.

16. Karthikeyan K, Guhathakarta S, Rajaram R, Korrapati PS. Electrospun zein/eudragit nanofibers based dual drug delivery system for the simultaneous delivery of aceclofenac and pantoprazole. Int J Pharm. 2012; 438(1):117-122.

17. Aduba DC, Hammer JA, Yuan Q, Yeudall WA, Bowlin GL, Yang H. Semi-interpenetrating network (sIPN) gelatin nanofiber scaffolds for oral mucosal drug delivery. Acta Biomater. 2013;9(5):6576-6584.

18. El-Shabouri MH, El-Aleem HMA, Soliman OA, El-Dahhan MS. Formulation and evaluation of buccoadhesive tablets. B Pharm Sci. 2009;32:45-64.
19. Tungprapa S, Jangchud I, Supaphol P. Release characteristics of four model drugs from drug-loaded electrospun cellulose acetate fiber mats. Polymer. 2007:48(17):5030-5041.

20. Hayton WL, Chen T. Correction of perfusate concentration for sample removal. J Pharm Sci. 1982;71(7):820-821.

21. Wen MM, El-Kamel AH, Khalil SA. Systemic enhancement of papaverine transdermal gel for erectile dysfunction. Drug Dev Ind Pharm. 2012;38(8):912-922.

22. Lipman NS, Marini RP, Erdman SE. A comparison of ketamine/xylazine and ketamine/xylazine/acepromazine anesthesia in the rabbit. $J \mathrm{Am}$ Assoc Lab Anim Sci. 1990;40(4):395-398.

23. Yoshino F, Yoshida A, Nakajima A, Wada-Takahashi S, Takahashi S-S, Lee MC-I. Alteration of the redox state with reactive oxygen species for 5-fluorouracil-induced oral mucositis in hamsters. PLoS One. 2013; 8(12):e82834.

24. Hitomi S, Ono K, Yamaguchi K, et al. The traditional Japanese medicine hangeshashinto alleviates oral ulcer-induced pain in a rat model. Arch Oral Biol. 2016;66:30-37.

25. Choi JS, Han SH, Hyun C, Yoo HS. Buccal adhesive nanofibers containing human growth hormone for oral mucositis. J Biomed Mater Res B Appl Biomater. 2016;104(7):1396-1406.

26. Tyagi C, Tomar L, Choonara YE, Du Toit LC, Kumar P, Pillay V. Electrospun nanofiber matrix with a mucoadhesive backing film for oramucosal drug delivery. Int J Mater Mech Manuf. 2014; 2:81-85.

27. Li Z, Wang C. Chapter 2: Effects of working parameters on electrospinning. One-Dimensional Nanostructures. Berlin, Heidelberg: Springer; 2013:15-28.

28. Zong X, Kim K, Fang D, Ran S, Hsiao BS, Chu B. Structure and process relationship of electrospun bioabsorbable nanofiber membranes. Polymer. 2002;43(16):4403-4412.

29. Buchko CJ, Chen LC, Shen Y, Martin DC. Processing and microstructural characterization of porous biocompatible protein polymer thin films. Polymer. 1999;40(26):7397-7407.

30. Fong H, Chun I, Reneker D. Beaded nanofibers formed during electrospinning. Polymer. 1999;40(16):4585-4592.

31. Asgarzadeh F, Edgar R, Li J, Moß J, Nollenberger K. Rheological Characterisation of (Meth)acrylic Copolymers Suitable for Melt Extrusion Applications. CRS 2011 Poster Abstracts \# 749. Pharma Polymers Booth (No 21). Available from: http://eudragit.evonik.com/ sites/lists/HN/Documents/evonik-pharma-polymers-news-1-2011-EN. pdf. Accessed March 14, 2016.

32. Gatti JW, Smithgall MC, Paranjape SM, Rolfes RJ, Paranjape M. Using electrospun poly (ethylene-oxide) nanofibers for improved retention and efficacy of bacteriolytic antibiotics. Biomed Microdevices. 2013; 15(5):887-893.

33. Pillay V, Dott C, Choonara YE, et al. A review of the effect of processing variables on the fabrication of electrospun nanofibers for drug delivery applications. J Nanomater. 2013;2013:1-22.

34. Ki CS, Baek DH, Gang KD, Lee KH, Um IC, Park YH. Characterization of gelatin nanofiber prepared from gelatin-formic acid solution. Polymer. 2005;46(14):5094-5102.

35. Pham QP, Sharma U, Mikos AG. Electrospinning of polymeric nanofibers for tissue engineering applications: a review. Tissue Eng. 2006;12(5):1197-1211.

36. Reneker DH, Chun I. Nanometre diameter fibres of polymer, produced by electrospinning. Nanotechnology. 1996;7(3):216-233.

37. Zhang C, Yuan X, Wu L, Han Y, Sheng J. Study on morphology of electrospun poly (vinyl alcohol) mats. Eur Polym J. 2005;41(3):423-432.

38. Kanani AG, Bahrami SH. Effect of changing solvents on poly ( $\varepsilon$-caprolactone) nanofibrous webs morphology. J Nanomater. 2011; 2011:31.

39. Theron S, Zussman E, Yarin A. Experimental investigation of the governing parameters in the electrospinning of polymer solutions. Polymer. 2004;45(6):2017-2030.

40. Zeng J, Xu X, Chen X, et al. Biodegradable electrospun fibers for drug delivery. J Control Release. 2003;92(3):227-231. 
41. Zamani M, Morshed M, Varshosaz J, Jannesari M. Controlled release of metronidazole benzoate from poly $\varepsilon$-caprolactone electrospun nanofibers for periodontal diseases. Eur J Pharm Biopharm. 2010;75(2): $179-185$.

42. Xu X, Zhong W, Zhou S, Trajtman A, Alfa M. Electrospun PEG-PLA nanofibrous membrane for sustained release of hydrophilic antibiotics. J Appl Polym Sci. 2010;118(1):588-595.

43. Park J-Y, Lee I-H. Controlled release of ketoprofen from electrospun porous polylactic acid (PLA) nanofibers. J Polym Res. 2011;18(6): 1287-1291.

44. El-Kamel A, Sokar M, Al Gamal S, Naggar V. Preparation and evaluation of ketoprofen floating oral delivery system. Int J Pharm. 2001; 220(1):13-21.

45. Illangakoon UE, Nazir T, Williams GR, Chatterton NP. Mebeverineloaded electrospun nanofibers: physicochemical characterization and dissolution studies. J Pharm Sci. 2014;103(1):283-292.

46. Auda SH, Ahmed MM, El-Rasoul SA, Saleh K. Formulation and physicochemical characterization of piroxicam containing polymer films. Bull Pharm Sci. 2010;33:33-42.

47. Yu D-G, Li X-Y, Wang X, Chian W, Liao Y-Z, Li Y. Zero-order drug release cellulose acetate nanofibers prepared using coaxial electrospinning. Cellulose. 2013;20(1):379-389.

48. Deshmane SV, Channawar MA, Chandewar AV, Joshi UM, Biyani KR. Chitosan based sustained release mucoadhesive buccal patches containing verapamil $\mathrm{HCl}$. Int J Pharm. 2009;1(1):216-229.

49. Deore V, Kumar R, Gide P. Development and statistical optimization of mucoadhesive buccal patches of indomethacin: in-vitro and ex-vivo evaluation. IJAPBC. 2013;2(2):405-422.

50. Nikam VK, Kotade KB, Gaware VM, Dhamak R, Somwanshi SB, Khadse AN. Eudragit a versatile polymer: a review. Pharmacol Online. 2011;1(1):152-164.

51. Sill TJ, von Recum HA. Electrospinning: applications in drug delivery and tissue engineering. Biomaterials. 2008;29(13):1989-2006.
52. Gowthamarajan K, Jawahar N, Wake P, Jain K, Sood S. Development of buccal tablets for curcumin using Anacardium occidentale gum. Carbohydr Polym. 2012;88(4):1177-1183.

53. Puratchikody A, Prasanth V, Mathew S, Kumar B. Development and characterization of mucoadhesive patches of salbutamol sulfate for unidirectional buccal drug delivery. Acta Pharm. 2011;61(2):157-170.

54. Garg T, Malik B, Rath G, Goyal AK. Development and characterization of nano-fiber patch for the treatment of glaucoma. Eur J Pharm Sci. 2014;53:10-16.

55. Yu D-G, Branford-White C, White K, Li X-L, Zhu L-M. Dissolution improvement of electrospun nanofiber-based solid dispersions for acetaminophen. AAPS PharmSciTech. 2010;11(2):809-817.

56. Suwantong O, Ruktanonchai U, Supaphol P. Electrospun cellulose acetate fiber mats containing asiaticoside or Centella asiatica crude extract and the release characteristics of asiaticoside. Polymer. 2008;49(19): 4239-4247.

57. Haque T, Talukder MMU, Laila S, Fatema K, Islam MS, Reza MS Model dependent and independent approaches to compare in vitro release profiles from ethylcellulose and Eudragit L100 based matrix tablets. J Pharm Sci. 2009;8:89-98.

58. Mei L, Wang YL, Tong AP, Guo G. Facile electrospinning of an efficient drug delivery. Expert Opin Drug Deliv. 2016;25:1-13.

59. Cavalcante GM, Sousa de Paula RJ, Souza LP, Sousa FB, Mota MR, Alves AP. Experimental model of traumatic ulcer in the cheek mucosa of rats. Acta Cir Bras. 2011;26(3):227-234.

60. de Sousa Sá OM, Lopes NNF, Alves MTS, Lalla RV, Oliva MLV, Caran EMM. Glycine supplementation reduces the severity of chemotherapy-induced oral mucositis in hamsters. Nat Sci. 2013;5(09): 972-978.

61. Dai X-Y, Nie W, Wang Y-C, Shen Y, Li Y, Gan S-J. Electrospun emodin polyvinylpyrrolidone blended nanofibrous membrane: a novel medicated biomaterial for drug delivery and accelerated wound healing. J Mater Sci Mater Med. 2012;23(11):2709-2716.
International Journal of Nanomedicine

\section{Publish your work in this journal}

The International Journal of Nanomedicine is an international, peerreviewed journal focusing on the application of nanotechnology in diagnostics, therapeutics, and drug delivery systems throughou the biomedical field. This journal is indexed on PubMed Central,

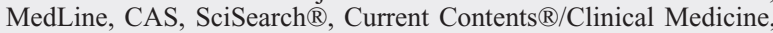

\section{Dovepress}

Journal Citation Reports/Science Edition, EMBase, Scopus and the Elsevier Bibliographic databases. The manuscript management system is completely online and includes a very quick and fair peer-review system, which is all easy to use. Visit http://www.dovepress.com/ testimonials.php to read real quotes from published authors. 